\title{
BMJ Open To what extent are surgery and invasive procedures effective beyond a placebo response? A systematic review with meta-analysis of randomised, sham controlled trials
}

\author{
Wayne B Jonas, ${ }^{1}$ Cindy Crawford, ${ }^{1}$ Luana Colloca, ${ }^{2,3}$ Ted J Kaptchuk, ${ }^{4}$ \\ Bruce Moseley, ${ }^{5}$ Franklin G Miller, ${ }^{6}$ Levente Kriston, ${ }^{7}$ Klaus Linde, ${ }^{8}$ Karin Meissner ${ }^{9}$
}

To cite: Jonas WB, Crawford C, Colloca L, et al. To what extent are surgery and invasive procedures effective beyond a placebo response? A systematic review with meta-analysis of randomised, sham controlled trials. BMJ Open 2015;5: e009655. doi:10.1136/ bmjopen-2015-009655

- Prepublication history and additional material is available. To view please visit the journal (http://dx.doi.org/ 10.1136/bmjopen-2015009655).

Received 10 August 2015 Revised 28 October 2015 Accepted 5 November 2015

CrossMark

For numbered affiliations see end of article.

Correspondence to Dr Wayne B Jonas; wjonas@siib.org

\section{ABSTRACT}

Objectives: To assess the quantity and quality of randomised, sham-controlled studies of surgery and invasive procedures and estimate the treatment-specific and non-specific effects of those procedures.

Design: Systematic review and meta-analysis. Data sources: We searched PubMed, EMBASE, CINAHL, CENTRAL (Cochrane Library), PILOTS, PsycInfo, DoD Biomedical Research, clinicaltrials.gov, NLM catalog and NIH Grantee Publications Database from their inception through January 2015.

Study selection: We included randomised controlled trials of surgery and invasive procedures that penetrated the skin or an orifice and had a parallel sham procedure for comparison.

Data extraction and analysis: Three authors independently extracted data and assessed risk of bias. Studies reporting continuous outcomes were pooled and the standardised mean difference (SMD) with 95\% Cls was calculated using a random effects model for difference between true and sham groups.

Results: 55 studies ( 3574 patients) were identified meeting inclusion criteria; 39 provided sufficient data for inclusion in the main analysis (2902 patients). The overall SMD of the continuous primary outcome between treatment/sham-control groups was 0.34 (95\% Cl 0.20 to $\left.0.49 ; p<0.00001 ; I^{2}=67 \%\right)$. The SMD for surgery versus sham surgery was non-significant for pain-related conditions $(n=15, S M D=0.13, p=0.08)$, marginally significant for studies on weight loss $(n=10$, $\mathrm{SMD}=0.52, \mathrm{p}=0.05)$ and significant for gastroesophageal reflux disorder (GERD) studies $(n=5$, $S M D=0.65, p<0.001)$ and for other conditions $(n=8$, $S M D=0.44, p=0.004$ ). Mean improvement in sham groups relative to active treatment was larger in painrelated conditions $(78 \%)$ and obesity $(71 \%)$ than in GERD $(57 \%)$ and other conditions $(57 \%)$, and was smaller in classical-surgery trials $(21 \%)$ than in endoscopic trials $(73 \%)$ and those using percutaneous procedures $(64 \%)$.

Conclusions: The non-specific effects of surgery and other invasive procedures are generally large.

Particularly in the field of pain-related conditions,

\section{Strengths and limitations of this study}

- This is the first systematic review using a meta-analysis approach to estimate both specific and non-specific components in sham-controlled surgical trials, and to what extent those effects differ among conditions and procedures.

- All sensitivity analyses showed similar results as the main analysis, except one, namely the sensitivity analysis for large studies ( $\geq 100$ patients), which showed a smaller non-significant effect size.

- Our results have implications for clinical research and practice by arguing against the continued use of ineffective invasive treatments, especially in the field of chronic pain

- One limitation might be that the conclusions from our meta-analysis are restricted to available published data on surgical interventions that have been tested in sham-controlled clinical trials.

more evidence from randomised placebo-controlled trials is needed to avoid continuation of ineffective treatments.

\section{INTRODUCTION}

Surgery and other invasive procedures such as endoscopy and percutaneous procedures are widely used in medicine but their specific efficacy and risk-benefit profile are rarely assessed in rigorous and systematic ways. The development of minimally invasive procedures has expanded the use of such interventions for treating a variety of conditions such as low-back pain, ${ }^{1}$ arthritis, ${ }^{2}$ endometriosis, ${ }^{3}$ Parkinson's disease ${ }^{4}$ gastro-oesophageal reflux $^{5}$ and obesity. ${ }^{6}$ 
Rarely are these procedures evaluated using rigorous research designs involving randomisation, allocation concealment and blinding or placebo controls, which are considered gold standards for medical interventions. In the absence of controls for common sources of bias, studies on these procedures may give a false impression of their true efficacy. Is it possible to test invasive procedures using rigorous methods? Blinding of outcome assessment is challenging since mimicking a complex, invasive procedure such as surgery, or insertion of a scope or a needle, requires an elaborate sham procedure. Moreover, there is significant controversy over the ethics of using sham procedures, even with carefully informed patients, further restricting the number of such studies being carried out. ${ }^{78}$ However, can we justify widespread use of these procedures without rigorous testing?

The use of blinded, sham procedures permits rigorous assessment of treatment efficacy by comparing the outcome in the treatment and sham groups. Specifically, sham procedures control for a variety of observed outcomes in the sham group that are distinct from the specific efficacy of the surgery or invasive procedure under investigation. These 'non-specific' outcomes include placebo responses (also sometimes called placebo effects), which we define here as the observed outcome changes in the sham groups. These changes are due to the natural history of the patient's condition or regression to the mean and a response to the ritual of medical treatments. Such rituals include the type of procedure (pill, needle, knife or touch), the status, authority and communication style of the provider, the setting and context of the treatment and the patient's and practitioners expectation about the outcome. ${ }^{9}$

Yet, invasive procedures are thought to incorporate many factors that may contribute to the placebo responses including use of a hospital-like setting; multiple, authoritative providers; frequent and repeated suggestions about expected outcomes; a physical invasion of the body; and an elaborate ritual of treatment delivery and recovery. ${ }^{10}$ Thus, one would expect a significant contribution from surgical ritual and other non-specific factors to the observed outcomes during invasive procedures in clinical practice and in randomised trials without sham control groups. Several high profile studies support this hypothesis in which sham procedures involving only superficial anaesthesia were compared to the more invasive true procedure. ${ }^{11-13}$ For example, Moseley et $a l^{11}$ reported no greater pain improvement in patients with osteoarthritis of the knee that underwent arthroscopic knee surgery compared to a sham procedure in which a cut was made over the knee without introducing the arthroscope. Two more recent controlled studies of vertebroplasty for painful osteoporotic vertebral fractures reported similar degrees of pain relief from sham procedures involving only superficial anaesthesia compared to the more invasive active procedures. $^{12}{ }^{13}$ In contrast, a systematic review comparing surgical with non-surgical treatments for painful osteoporotic vertebral fractures came to the conclusion that vertebroplasty and kyphoplasty are superior to non-surgical treatments. ${ }^{14}$ Since invasive interventions frequently go along with larger non-specific effects than non-invasive treatments ${ }^{15}{ }^{16}$ surgical trials that do not include a sham surgery arm may give biased results. Thus, the efficacy of invasive procedures, for example, for chronic pain conditions, remains controversial. ${ }^{17}$ In addition, many invasive procedures involve the risk of anaesthesia and high cost. ${ }^{17}$ Therefore, it is important to estimate to what degree the observed outcomes from invasive procedures are due to specific efficacy of the treatments or to other factors.

To better understand these issues we conducted a systematic review and meta-analysis of studies on surgery and invasive procedures in which a parallel sham procedure was included for comparison. Our study aims were to: (1) assess the quantity and quality of such studies; (2) estimate the magnitude of specific effects over sham procedures; and, (3) estimate the contribution of the surgical ritual and other non-specific factors to outcomes from these procedures.

\section{METHODS}

\section{Identification of studies}

The following online databases were searched from their inception through January 2015: PubMed, EMBASE, CINAHL, CENTRAL (Cochrane Library), PILOTS, PsycInfo, DoD Biomedical Research, clinicaltrials.gov, NLM catalog, as well as NIH Grantee Publications Database. We used as our initial search terms: 'Diagnostic Techniques, Surgical' OR 'Orthopedic Procedures' OR 'Specialties, Surgical' OR 'Surgical Procedures, Operative' OR 'surgery' (Subheading) or surgery) AND ('Placebos' OR 'Placebo Effect' or sham surg* or placebo surg* or mock surg* or simulated surg* or placebo proc* or sham proc* or mock proc* or simulated $\left.\operatorname{proc}^{*}\right)$. We restricted our search to humans and randomised controlled trials. Variations of these search terms were made for MESH terms, where necessary, and are available on request from the first author.

The 'Grey literature' was searched by looking for relevant dissertations, conference proceedings, Google Scholar and searching the internet using the keyword scheme as well as searching all relevant reference lists of identified articles and related reviews. We also contacted and consulted with leading experts in the fields of surgery and placebo, and shared databases that these experts have collected over the years relating to placebo to make sure we captured all the relevant literature.

\section{Eligibility criteria}

Studies were included in the systematic review if they: (1) were randomised controlled trials; (2) involved a population for which there was a symptom-driven medical condition for which an invasive procedure or 
classical surgery as defined below was being performed; and (3) had a comparison group that used a sham procedure to mimic the real procedure.

Classical surgery was defined as a procedure that followed the typical surgical experience that uses preoperative preparation, anaesthesia, an incisional trauma (usually through muscle and fascia and into the peritoneum) and a postoperative recovery process. Invasive procedures were defined as when an instrument was inserted into the body (either endoscopically or percutaneously) for the purpose of manipulating tissue or changing anatomy. In all cases we selected studies where when these procedures were compared to a sham procedure that used the same surgical or invasive procedure, instrument and ritual, but eliminated the hypothesised active component of tissue manipulation. We excluded studies in which the procedure was used simply as a delivery mechanism for another ongoing active treatment such as a pacemaker, brain or cardiac stimulation, or delivery of a drug or biological product. Studies where an invasive procedure was implemented for prevention of a medical condition or there was no symptom-driven condition were also excluded.

Four investigators (CC, LC, KL and KM) screened titles and abstracts for relevance in two phases based on the inclusion criteria: phase one eliminated all clearly irrelevant studies, phase two applied all inclusion/exclusion criteria listed above for the remaining studies. Any disagreements about including a study were resolved through discussion and consensus, and approved by the first author (WJ). All reviewers were fully trained in systematic review methodology. At least two reviewers had to review each citation in order for it to progress to the next phase of the review. A Cohen's $\kappa$ on agreement was attained for both phases above $88 \%$.

\section{Quality assessment and data extraction}

The methodological quality of the individual studies (sequence generation, allocation concealment, was assessed independently by three reviewers using the Cochrane Risk of Bias (ROB) tool. ${ }^{18}$ Descriptive data was independently extracted on the following items: population; condition for which surgery was performed; sample (population) entered; dropout rate; informed consent details; whether a power calculation was performed and achieved; intervention and sham procedure used; primary and secondary outcomes and the statistical data associated with these; whether expectation was reported; author conclusions; adverse events reported; funding source, and reviewer comments. We also extracted from each study, if available, a continuous and a dichotomous main outcome at two time points (intermediate and late), and a continuous and a dichotomous pain outcome (when applicable). The most important outcome measure (miOM) was defined as either: (1) the primary main outcome measure $(\mathrm{pMOM})$ at a time point as predefined in the trial; or (if not 1), (2) the only major outcome of a trial at the latest available time point; or (if neither 1 nor 2), (3) the clearly most relevant outcome determined by two independent reviewers at the latest available time point. Secondary outcomes were intermediate time points of the most important outcome measure; pain outcomes at the latest available time point; or, pain outcomes at the intermediate time point. All discrepancies were tracked by the review manager and were resolved by consensus and discussions during team meetings. Data were entered into a webbased, secure, systematic review management programme called Mobius Analytics SRS (Mobius Analytics Inc, Ottawa, Ontario, Canada).

\section{Data synthesis and analysis}

According to our analysis plan, the meta-analyses focused on continuous outcomes. The primary analysis was based on trials reporting a most important continuous outcome measure in sufficient detail to be included in the meta-analysis. Secondary analyses were based on trials reporting (1) a continuous outcome measure at an intermediate time point, (2) a pain measure at a late time point, (3) a pain measure at an intermediate time point. Trials reporting only a dichotomous outcome measure (responder data) are noted in online supplementary table 1 , and a sensitivity analysis was computed for these outcomes (see below).

Within-group and between-group effect sizes were based on Cohen's ${ }^{19} \mathrm{~d}$ for change within one group, and Cohen's d for between-group effect measures, respectively, correcting for small-sample bias. ${ }^{20}$ In order to keep the effect size framework coherent for within-group and between-group designs, change from baseline was used throughout. When SD was not reported, it was calculated from pre-SD and post-SD, ${ }^{21}$ using $\mathrm{r}=0.5$ for the product-moment correlation between pre and post measures.

Analyses of continuous data were performed with the generic inverse variance module of the Cochrane Collaboration's Review Manager software (V.5.1), using standardised mean difference (SMD) as the effect size measure. As we expected heterogeneity, a random effects model was used. Within-group effect sizes were pooled in such a way that positive values indicate improvement, while positive values of between-group effect sizes indicate superiority (more pronounced improvement) of the intervention group over the control (sham) group. To estimate the relative contribution of non-specific outcomes to treatment effects, the per cent ratio of the pooled within-group treatment effects in the sham and the treatment groups was calculated. We used Cochrane's $Q$ test and calculated $\mathrm{I}^{2}$ to examine statistical heterogeneity, with low, moderate and high $\mathrm{I}^{2}$ values of $25 \%, 50 \%$, and $75 \%$. $^{22}$ Egger's test was used to assess funnel plot asymmetry. ${ }^{23}$ A $p$ value of less than 0.05 was set as the level of significance. ${ }^{24} 25$

Subgroup analyses were performed according to predefined categories of target diseases and types of 
surgery. To check the robustness of results, we performed sensitivity analyses with four criteria: (1) studies specifying a primary main outcome measure (pMOM); (2) imputing 0.3 and 0.7 for pre-post correlation coefficient $r$, when missing; (3) studies with total sample sizes $\geq 100$; and, (4) studies with low risk of allocation concealment. An additional sensitivity analysis was performed for dichotomous outcomes of 12 studies that provided no continuous outcome (see online supplementary figure 1 ).

\section{RESULTS}

\section{Eligible studies}

Our search identified a total of 7360 citations. After excluding clearly irrelevant references the full text of 113 publications were obtained. Of these, 46 were excluded, mainly for not including an instrumental or surgical intervention or a sham procedure as defined above. A total of 55 studies (in 67 publications) involving a total of 3574 enrolled patients met our inclusion criteria for systematic review (figure 1). ${ }^{26}$

\section{Characteristics and quality of included studies}

Characteristics of the included studies are summarised in online supplementary table 1 . About half (25) of the studies were carried out on pain-related conditions with back pain (7) being the most frequent ${ }^{11}{ }^{1227-31}$ followed by arthritis (4), ${ }^{13} 32-34$ angina from coronary artery disease (4) ${ }^{35-39}$ ) abdominal pain (3), ${ }^{40-42}$ endometriosis (3) ${ }^{43-47}$ cholia (2) ${ }^{48} 49$ and migraine (2).$^{50}$ ) The most frequently studied non-pain condition was obesity, especially when using balloon insertion (11) ${ }^{52-62}$ ) Other conditions that had more than one study included gastroesophageal reflux disease (GERD) (5), ${ }^{63-67}$ Parkinson's Disease (2), ${ }^{68-74}$ sleep apnoea (2), ${ }^{75} 76$ dry eye (2) ${ }^{77} 78$ and asthma (2). ${ }^{79-81}$ Some other conditions were also studied (see online supplementary table 1) ${ }^{80-90}$ Many (22) of the studies involved endoscopic or percutaneous procedures in which tissue was removed or altered or a material (eg, dye, cement, balloon) was inserted. ${ }^{11-13}$ $2831343840-4352545661636567$ 77-79 90 Some of these procedures used a catheter to reach an internal organ (such as the heart or gall bladder) or a needle to inject a material or cell (often into the lumbar spine or
Figure 1 Flow chart of included studies. RCT, randomised controlled trial.

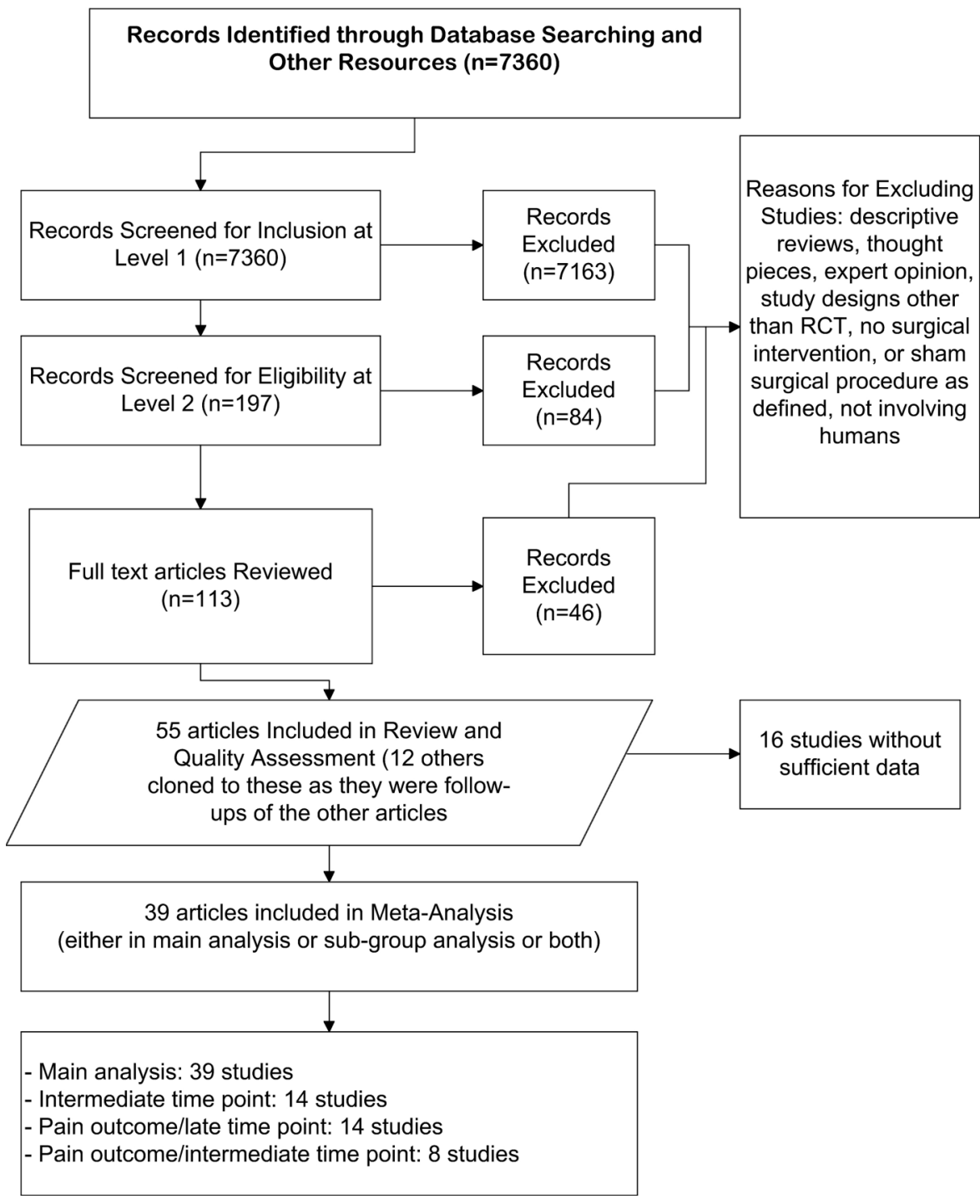


brain). ${ }^{2729} 303253555759606264668589$ Five studies evaluated more classical surgical procedures in which the body was opened with a scalpel or drill. ${ }^{50} 5174-76$

In most studies, blinding was achieved using elaborate sham procedures. Those mimicking classical surgical procedures usually cut the body, leaving a scar but causing less damage than the real surgery. Sham percutaneous and endoscopic procedures often involved superficial insertion of a needle or a scope. For example, in the Parkinson's studies on surgical interventions on the brain, sham procedures involved placing burr holes without penetration of the skull. ${ }^{68-74}$ Sham surgery for endometriosis would often involve 'diagnostic laparoscopy' with no internal tissue destruction. Sham balloon insertion for obesity treatment usually involved inserting the balloon but not inflating it. ${ }^{52-62}$

Overall, the risk of bias was low in these studies, with some exceptions. Of the 55 studies (67 publications) included in the systematic review, 34 studies (62\%) reported an adequate method for generating the allocation sequence, however only $23(42 \%)$ had adequate concealment of allocation. Blinding of the patients and outcome assessors was adequate in 48 (87\%) studies and incomplete data was adequately addressed in 52 (95\%). Fifty-two $(95 \%)$ of the studies were free from suggestion of selective outcome reporting and 53 studies were judged to be free of other sources of bias.

\section{Overall analyses}

Thirty-nine studies (2902 patients) with continuous data were included in the main analysis. The overall effect of surgery compared to sham surgery was highly significant (SMD $0.34,95 \%$ CI 0.20 to $0.49 ; \mathrm{p}<0.00001$ ), while heterogeneity was large $\left(\mathrm{I}^{2}=67 \%, \mathrm{p}<0.00001\right)$. Excluding one outlier ${ }^{52}$ reduced $\mathrm{I}^{2}$ to $57 \%$ (SMD, 0.30, 95\% CI 0.17 to $0.43 ; \mathrm{p}<0.00001)$, indicating moderate heterogeneity. Sensitivity analyses provided comparable effect sizes (figure 2), except for studies with overall sample sizes of 100 participants or more, for which the SMD was nonsignificant at $0.15(\mathrm{n}=10 ; 95 \%$ CI -0.02 to $0.32 ; \mathrm{p}=0.09$; $\mathrm{I}^{2}=66 \%$ ). Inspection of the funnel plot suggests the presence of biases in the meta-analysis, such as small study bias or publication bias (figure 3). Asymmetry in the funnel plot was confirmed by the Egger's test (asymmetry coefficient $1.7, \mathrm{p}=0.017$ ).

Non-significant SMD were found when combining available data for the most important continuous outcome measure at an intermediate time point $(n=14$; SMD $0.12,95 \%$ CI -0.05 to $0.29 ; \mathrm{p}=0.17 ; \mathrm{I}^{2}=54 \%$ ) as well as for specific pain outcomes at a late $(n=14$; SMD $0.12,95 \%$ CI -0.03 to $0.27 ; \mathrm{p}=0.11 ; \mathrm{I}^{2}=29 \%$;) or an intermediate time point $(\mathrm{n}=8$; SMD $0.07,95 \%$ CI -0.06 to $\left.0.20 ; \mathrm{p}=0.31 ; \mathrm{I}^{2}=0 \%\right)$.

\section{Subgroup analyses of most important outcome measures} Subgroups by condition

Figure 4 summarises the SMD and subgroup means for between-group changes and the $95 \%$ CIs for each condition. The overall test for subgroup differences was significant $\left(\chi^{2}=10.26, p=0.04\right)$, indicating significant heterogeneity of SMD between subgroups. Fifteen studies (analysing 1584 patients) included in the meta-analysis investigated pain-related conditions, the overall SMD was non-significant at 0.13 (95\% CI -0.01 to 0.28 ; $\mathrm{p}=0.08$; $\mathrm{I}^{2}=46 \%$ ). Ten studies (287 patients) reported on weight loss, the SMD was marginally significant at $0.52(95 \%$ CI 0.01 to $\left.1.03 ; \mathrm{p}=0.05 ; \mathrm{I}^{2}=76 \%\right)$. Excluding one outlier ${ }^{52}$ reduced $\mathrm{I}^{2}$ to $14 \%$ (SMD $0.27,95 \%$ CI 0.00 to 0.55 ; $\mathrm{p}=0.05$ ). Most (nine) of these studies involved balloon and sham balloon insertion. Five studies (342 patients) involved GERD. They showed a significant SMD of 0.65 ( $95 \%$ CI 0.31 to $1.00 ; \mathrm{p}=0.0002 ; \mathrm{I}^{2}=55 \%$ ). One study on Parkinson's (34 patients) showed an SMD of 0.36 (95\% CI -0.37 to 1.09 ). Eight studies (655 patients) on other diseases yielded a pooled SMD of 0.44 (95\% CI 0.14 to $0.74, \mathrm{p}=0.004 ; \mathrm{I}^{2}=57 \%$ ).

\section{Subgroups by type of procedure}

Between-group SMD did not differ significantly between classical surgery, endoscopic surgery and percutaneous procedures $\left(\chi^{2}=1.10, \mathrm{p}=0.58\right.$; results not shown $)$.

\section{Dichotomous outcomes}

Twelve studies provided only a dichotomous outcome measure (see online supplementary table 1 ). Sensitivity analyses showed an overall effect of surgery compared to sham surgery (risk ratio $1.54,95 \%$ CI 1.11 to 2.15; $\mathrm{p}=0.01)$, while heterogeneity was large $\left(\mathrm{I}^{2}=59 \%\right.$, $\mathrm{p}=0.005$ ). Subgroup analyses according to condition revealed a significant effect of surgery versus sham surgery for pain studies $(\mathrm{n}=9$; risk ratio $1.60,95 \%$ CI 1.11 to $2.30 ; \mathrm{p}=0.01 ; \mathrm{I}^{2}=59 \%, \mathrm{p}=0.01$ ) but not for other studies $(\mathrm{n}=3$; risk ratio $2.19,95 \%$ CI 0.44 to $10.84 ; \mathrm{p}=0.33$; $\mathrm{I}^{2}=60 \%, \mathrm{p}=0.08$; see online supplementary figure 1 ).

\section{Changes from baseline within sham and active groups}

The pooled SMD for changes from baseline was 0.61 in the sham groups $(95 \%$ CI 0.47 to $0.75, \mathrm{p}<0.00001, \mathrm{n}=39$, $\mathrm{I}^{2}=76 \%$ ) and 0.92 (95\% CI 0.74 to $1.09, \mathrm{p}<0.00001$, $\mathrm{n}=39, \quad \mathrm{I}^{2}=86 \%$ ) in the treatment groups. Thus, on average, the changes in the sham groups accounted for $65 \%$ of the overall improvement from the treatments. This proportion of specific to non-specific treatment effects was larger in pain-related conditions $(78 \%)$ and obesity $(71 \%)$ than in GERD $(57 \%)$ and other conditions $(57 \%)$, and was considerably smaller in classical surgery trials $(21 \%)$ than in endoscopic trials $(73 \%)$ and those using percutaneous procedures (64\%; figure 4). Changes in the sham groups accounted for $89 \%$ and $82 \%$ of overall improvement in intermediate and late pain outcomes.

\section{DISCUSSION}

This is the first comprehensive systematic review with meta-analysis estimating the magnitude of the specific 
Figure 2 The specific effect of invasive procedures and surgery.

\section{Analysis, subgroup or study}

Overall analysis

Sensitivity analyses

Pre-post correlation coefficient $r=0.3$ Pre-post correlation coefficient $r=0.7$ Primary outcome clearly defined

Sample size at least 100

Low risk of allocation concealment

Low risk of unblinding

Subgroup analyses

Pain

Abdominal pain

Swank 2003

Subgroup $(95 \% \mathrm{Cl})$

Angina pectoris

Leon 2005

Subgroup $(95 \% \mathrm{Cl})$

Arthritis

Moseley 2002

Bradley 2002

Sihvonen 2013

Subgroup $(95 \% \mathrm{Cl})$

Endometriosis

Abbott 2004

Subgroup $(95 \% \mathrm{Cl})$

Back pain

van Kleef 1999

Leclaire 2001

Freeman 2005

Nath 2008

Buchbinder 2009

Kallmes 2009

Patel 2012

Subgroup $(95 \% \mathrm{Cl})$

Migraine

Dowson 2009

Guyuron 2009

Subgroup $(95 \% \mathrm{CI})$

Subtotal $(95 \% \mathrm{Cl})$

GERD

Corley 2003

Deviere 2005

Montgomery 2006

Rothstein 2006

Schwartz 2007

Subtotal $(95 \% \mathrm{Cl})$

Obesity

Lindor 1987

Meshkinpour 1988

Mathus-Vliegen 1990

Rigaud 1995

Mathus-Vliegen 1996

Mathus-Vliegen 2002

Mathus-Vliegen 2003

Martinez-Brocca 2007

Genco 2006

Gersin 2010

Subtotal $(95 \% \mathrm{Cl})$

Parkinson's

Olanow 2003

Subtotal $(95 \% \mathrm{CI})$

Other

Winters 1984

Larson 1998

Slusser 1998

Friedman 2008

Geldis 2008

Koutsourelakis 2008

Castro 2009

Rodriguez 2009

Subtotal $(95 \% \mathrm{CI})$

$\begin{array}{ccccc}\text { N analysed } & I^{2} & \text { ES }[95 \% \mathrm{Cl}] & \text { P-Value } \\ 2902 & 67 \% & 0.34[0.20 ; 0.49] & <0.00001 \\ & & & & \\ & & & & \\ 2902 & 65 \% & 0.33[0.19 ; 0.47] & <0.00001 \\ 2902 & 70 \% & 0.37[0.22 ; 0.52] & <0.00001 \\ 1325 & 66 \% & 0.29[0.07 ; 0.50] & 0.009 \\ 1741 & 66 \% & 0.15[-0.02 ; 0.32] & 0.09 \\ 1539 & 71 \% & 0.34[0.14 ; 0.54] & 0.0008 \\ 2861 & 71 \% & 0.36[0.21 ; 0.51] & <0.00001\end{array}$

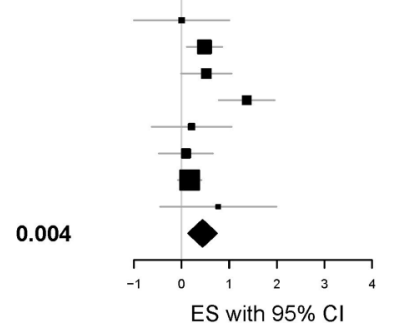

ES with $95 \% \mathrm{Cl}$ effects of surgery and invasive procedures for various conditions. While some high profile studies have reported no difference between treatment and sham procedures, we found a positive though modest overall effect size (Cohen's d) from the invasive procedures included in the analysis. When only larger studies $(\geq 100$ participants) are taken, the specific effects invasive procedures disappears, indicating the current evidence is 


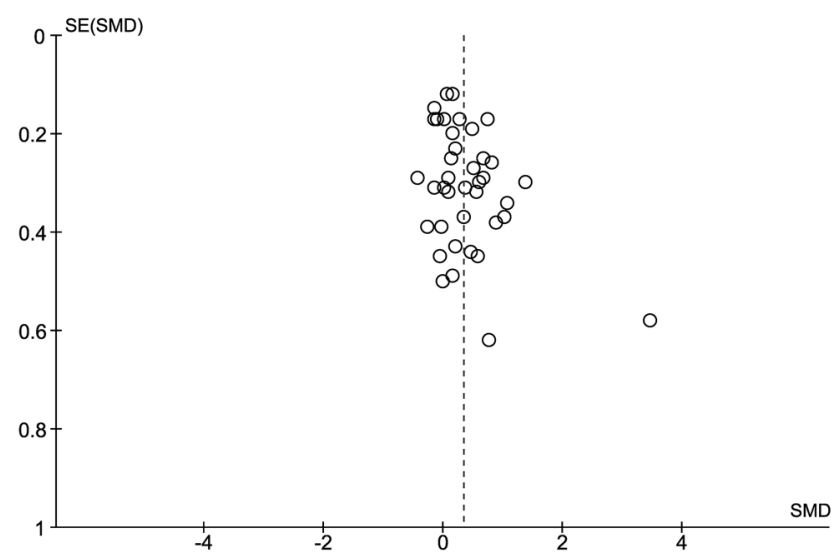

Figure 3 Funnel plot using continuous outcomes (effects of active vs sham treatment) of the 39 studies included in the main meta-analysis.

not strong and could be changed with more and better research. In addition, the contribution of non-specific effects is even more substantial for certain conditions and procedures. While non-specific effects accounted for approximately $65 \%$ of the effects from all invasive procedures, they made up to $78 \%$ of the active treatment effects in chronic pain conditions and $71 \%$ of the active treatment effects in obesity. These percentages are substantially higher than those observed in non-surgical trials, namely $40 \%$ for chronic pain conditions and $33 \%$ for obesity. ${ }^{91}$ The higher contribution of non-specific effects in surgical trials could well be the result of higher placebo effects. However, the lack of no-treatment groups in our data set (and other data set) ${ }^{92}$ allows no firm conclusion. ${ }^{91}$ Our subgroup analyses indicate that the current evidence does not support the specific efficacy of invasive procedures for chronic pain conditions $(p=0.08)$ and was borderline for obesity $(p=0.05)$, but does support these procedures for GERD $(p=0.0002)$. However, please note that the analysis of dichotomous outcomes showed a somewhat larger specific effect for pain studies (see online supplementary figure 1). There is insufficient data to make recommendations about the other conditions examined.

\section{Strengths and weakness of this study}

This study has several limitations. First, both the central strength and limitation of our study is that we pooled effect estimates of the included studies. We consider this a strength at is allows us to: (1) make an estimate of the overall effects of invasive procedures in sham-controlled surgical studies, (2) estimate the strength of confidence in the currently available data as to the specific efficacy of those procedures; and, (3) empirically investigate to what extent results differ between conditions and procedures. Obviously, it is not reasonable to expect that surgery has similar specific effects across conditions and outcomes so our subgroup estimates should not be interpreted clinically without considering how the interventions and outcomes varied. This is also indicated by the moderate-to-large heterogeneity in our meta-analyses, indicating more variation of effect sizes than would be expected by chance. Second, it is difficult to fully double-blind invasive procedures. While most studies successfully blinded patients and outcome assessors, physicians doing these procedures could not be blinded. Thus, it is possible that they communicated information to patients that biased the studies. Price and others have shown that physician expectations can influence pain outcomes even when restrictions are placed on verbal communication. ${ }^{93}$ Third, publication bias may play a role in the accuracy of our estimates. It is known that negative studies (in this case, studies showing no difference between real and sham procedures) are not published as frequently as positive studies. However, our search strategy was comprehensive and the study selection process was reliable. We also conducted a thorough search of the grey literature, as described above, and had input by experts in placebo research, increasing the likelihood of capturing all studies in this area. This activity allowed for a cross-check in the end to ensure we captured most of the relevant published randomised controlled trials for this review. We did not find any unpublished reports that met our inclusion criteria appropriate for this review, however there were some publications that were not readily accessible through the search engines commonly accessed that we were able to
Figure 4 Relative contribution to improvement in the placebo and active treatment groups.

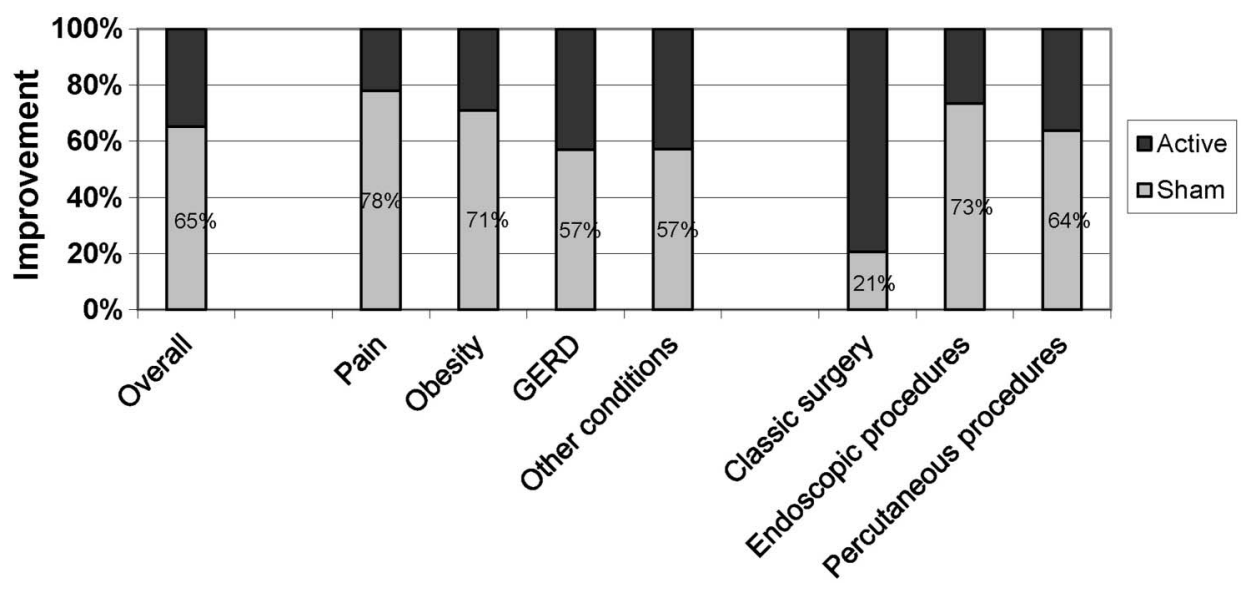


capture through these methods. Our sensitivity analyses on study quality factors did not change our primary findings, except restricting the analyses to large studies with 100 participants and above, revealed a considerably smaller, non-significant SMD at $0.15(95 \% \mathrm{CI}-0.02$ to $0.32 ; \mathrm{p}=0.09$ ). Egger's test for funnel plot asymmetry, however, suggested a small study bias in our data set. While our combined estimates of effect size must be considered crude for the overall meta-analysis, they are reasonable estimates for the pain, GERD and obesity subgroups. Meta-analyses of placebo-controlled drug studies in pain, depression, hypertension, ulcer treatment and other areas often report a similar magnitude of specific treatment effects compared to non-specific effects. ${ }^{95-98}$ Those studies, however, usually have much larger sample sizes, increasing confidence in their estimates. Finally, we found only one three-armed study that included no treatment, active and sham groups. ${ }^{67}$ Therefore, it is not possible to estimate the contribution that the ritual and context make to outcomes in invasive procedures compared to no treatment. Especially in the field of pain and obesity such three-armed studies would seem to be essential for making good evidence-based decisions.

Our findings are consistent with a systematic review published in the $B M J$ in $2014 .^{92}$ That study, however, used vote count and reported that $74 \%$ of 55 trials showed improvement in the placebo arm with $51 \%$ reporting no difference between surgery and placebo and $49 \%$ reporting surgery was superior to placebo. We have built on that study by doing a more comprehensive literature search and meta-analysis which allowed us to estimate the magnitude of surgical effects, the confidence in the current findings and to examine that magnitude across various quality parameters, conditions, procedures and outcomes. We can now conclude that at least chronic pain conditions lack clear evidence for the efficacy of the explored surgical interventions (eg, classic surgery and endoscopic procedures. Since these conditions represent a high public health burden worldwide we need to obtain better evidence for the use of these procedures. In addition, it is clear that the evidence from placebo controlled trials in the field as a whole is poor.

\section{Implications for practice, research and policy}

These results have a number of implications for practice, research and policy. The evidence from available shamcontrolled trials indicates that invasive procedures are not clearly more effective than sham procedures for various chronic pain conditions including endometriosis, back pain, arthritis, angina and migraine. There is evidence to support surgical interventions for GERD and limited evidence to support the use of balloon insertion for obesity.

Given the large number of invasive and surgical procedures being performed, it is noteworthy that we could identify only 55 sham-controlled studies in the literature.
Certainly, not all invasive procedures warrant shamcontrolled comparisons; for example, when results demonstrate indisputable changes in objective parameters the risks of sham procedures would be excessive. However, given that non-specific factors make a large contribution to the effects from invasive procedures for conditions like pain, more rigorous evaluation is needed before their widespread use is recommended for these conditions. A recent survey of surgeon's attitudes about sham surgery may provide an opportunity to conduct more such research. Surgeons generally agreed that a placebo component to surgical intervention might exist. ${ }^{99}$ Furthermore, results of a recent systematic review indicate that the risks of adverse effects associated with sham surgical procedures are small. ${ }^{92}$ Thus, more welldesigned sham-controlled surgical trials are warranted to avoid the continued use of ineffective invasive treatments.

\section{Author affiliations}

${ }^{1}$ Samueli Institute, Alexandria, Virginia, USA

${ }^{2}$ Department of Pain and Translational Symptom Science, School of Nursing, University of Maryland, Baltimore, Maryland, USA

${ }^{3}$ Department of Anesthesiology, School of Medicine, University of Maryland, Baltimore, Maryland, USA

${ }^{4}$ Program in Placebo Studies, Beth Israel Deaconess Medical Center, Harvard Medical School Boston, Massachusetts, USA

${ }^{5}$ The Methodist Hospital, Houston, Texas, USA

${ }^{6}$ Department of Bioethics, Clinical Center, National Institutes of Health, Bethesda, Maryland, USA

${ }^{7}$ Department of Medical Psychology, University Medical Center HamburgEppendorf, Hamburg-Eppendorf, Hamburg, Germany

${ }^{8}$ Institute of General Practice, Technische Universitat Munchen, Munich, Germany

${ }^{9}$ Institute of Medical Psychology, Ludwig-Maximilians-University Munich, Munich, Germany

Acknowledgements The authors would like to thank Ms LaDonna Johnson, Research Assistant at Samueli Institute for assistance with article retrieval and tracking, and Ms Viviane Enslein for assistance with manuscript preparation.

Contributors WBJ served as the PI on this project and was responsible for the conception and design of the project, obtaining funding, acquisition of data and interpretation of the data, drafting and final revision of the article, and final approval of the version submitted. CC served as the project manager and reviewer, and contributed to the conception and design of the systematic review, acquisition of data and analysis and interpretation of data, drafting the article, and approval of the version to be submitted. LC and KM served as study quality reviewers and contributed to the conception and design, acquisition of data, analysis and interpretation of data, drafting the manuscript and approval of the version to be submitted. In addition, KM led the meta-analysis section of the project. TJK and FGM served as subject matter experts, and were involved in the conception and design and interpretation of the data, revising the manuscript critically for important intellectual content and approval of the version to be submitted. LK served as the statistical expert on the project and was involved in the design and conduct of the meta-analysis, acquisition of data, analysis and interpretation of the data, contributing to the manuscript in statistics, meta-analysis techniques, the results section of the manuscript and approval of the version submitted. $\mathrm{KL}$ served in the conception and design, acquisition of the data, analysis and interpretation of the data, design of the meta-analysis technique for extracting data, assisted in drafting and revising the article for important intellectual content, and approval of the version to be submitted. 
Funding This work is supported by the US Army Medical Research and Materiel Command under Award number W81XWH-08-1-0615. The views, opinions and/or findings contained in this report are those of the author(s) and should not be construed as an official Department of the Army position, policy or decision unless so designated by other documentation. The funding source had no role in the design and conduct of the study, in the collection, analysis and interpretation of the data, or in the preparation, review, or approval of the manuscript.

Competing interests None declared.

Provenance and peer review Not commissioned; externally peer reviewed.

Data sharing statement No additional data are available.

Open Access This is an Open Access article distributed in accordance with the Creative Commons Attribution Non Commercial (CC BY-NC 4.0) license, which permits others to distribute, remix, adapt, build upon this work noncommercially, and license their derivative works on different terms, provided the original work is properly cited and the use is non-commercial. See: http:// creativecommons.org/licenses/by-nc/4.0/

\section{REFERENCES}

1. Friedly J, Standaert C, Chan L. Epidemiology of spine care: the back pain dilemma. Phys Med Rehabil Clin N Am 2010;21: 659-77.

2. Khanna A, Gougoulias N, Longo UG, et al. Minimally invasive total knee arthroplasty: a systematic review. Orthop Clin North Am 2009:40:479-89, viii.

3. Donnez J, Squifflet J, Donnez O. Minimally invasive gynecologic procedures. Curr Opin Obstet Gynecol 2011;23:289-95.

4. Politis M, Lindvall O. Clinical application of stem cell therapy in Parkinson's disease. BMC Med 2012;10:1.

5. Rosemurgy AS, Donn N, Paul H, et al. Gastroesophageal reflux disease. Surg Clin North Am 2011;91:1015-29.

6. Encinosa W, Bernard D, Steiner C, et al. Use and costs of bariatric surgery and prescription weight-loss medications. Health Aff 2005;24:1039-46.

7. Miller FG, Kaptchuk TJ. Sham procedures and the ethics of clinical trials. J R Soc Med 2004;97:576-8.

8. Miller FG, Wendler D. The ethics of sham invasive intervention trials. Clin Trials 2009;6:401-2.

9. Meissner K, Bingel U, Colloca L, et al. The placebo effect: advances from different methodological approaches. J Neurosci 2011;31:16117-24.

10. Johnson A. Surgery as placebo. Lancet 1994;344:1140-2.

11. Moseley JB Jr., O'Malley K, Petersen NJ, et al. A controlled trial of arthroscopic surgery for osteoarthritis of the knee. New Engl J Med 2002;347:81-8

12. Buchbinder $\mathrm{R}$, Osborne $\mathrm{RH}$, Ebeling $\mathrm{PR}$, et al. A randomized trial of vertebroplasty for painful osteoporotic vertebral fractures. $N$ Engl J Med 2009;361:557-68.

13. Kallmes DF, Comstock BA, Heagerty PJ, et al. A randomized trial of vertebroplasty for osteoporotic spinal fractures. $N$ Engl J Med 2009;361:569-79.

14. Papanastassiou ID, Phillips M, Van Meirhaeghe J, et al. Comparing effects of kyphoplasty, vertebroplasty, and non-surgical management in a systematic review of randomized and non-randomized controlled studies. Eur Spine J 2012;21:1826-43.

15. Meissner K, Fässler M, Rücker G, et al. Differential effectiveness of placebo treatments: a systematic review of migraine prophylaxis. JAMA Intern Med 2013;173:1941-51.

16. Bannuru RR, McAlindon TE, Sullivan MC, et al. Effectiveness and implications of alternative placebo treatments: a systematic review and network meta-analysis of osteoarthritis trials. Ann Intern Med 2015;163:365-72.

17. Schauer PR, Kashyap SR, Wolski K, et al. Bariatric surgery versus intensive medical therapy in obese patients with diabetes. $N$ Engl J Med 2012;366:1567-76.

18. Higgins J. Chapter 8: assessing risk of bias of included studies. In: Higgins J, Green S, eds. Cochrane handbook of systematic reviews of interventions. Wiley Online Library, 2008. http://handbook. cochrane.org/chapter_8/8_assessing_risk_of_bias_in_included studies.htm

19. Cohen J. Statistical power analysis for the behavioral sciences. 2nd edn. Hillsdale, NJ: Erlbaum, 1988.

20. Hedges L. Estimation of effect size from a series of independent experiments. Psychol Bull 1982;92:490-9.
21. Follmann D, Elliott $\mathrm{P}$, Suh I, et al. Variance imputation for overviews of clinical trials with continuous response. J Clin Epidemiol 1992;45:769-73.

22. Higgins J, Thompson S, Deeks J, et al. Measuring inconsistency in meta-analyses. BMJ 2003;327:557-60.

23. Egger M, Smith GD, Schneider $M$, et al. Bias in meta-analysis detected by a simple, graphical test. BMJ 1997;315:629-34.

24. DerSimonian R, Laird N. Meta-analysis in clinical trials. Control Clin Trials 1986;7:177-88.

25. Higgins J, Green S, eds. Cochrane handbook for systematic reviews of interventions. Chichester: Wiley-Blackwell, 2008.

26. Liberati A, Altman DG, Tetzlaff J, et al. The PRISMA statement for reporting systematic reviews and meta-analyses of studies that evaluate health care interventions: explanation and elaboration. Ann Intern Med 2009;151:W65-94.

27. Freeman BJ, Fraser RD, Cain $\mathrm{CM}$, et al. A randomized, double-blind, controlled trial: intradiscal electrothermal therapy versus placebo for the treatment of chronic discogenic low back pain. Spine (Phila Pa 1976) 2005;30:2369-77; discussion 78

28. Leclaire R, Fortin L, Lambert R, et al. Radiofrequency facet joint denervation in the treatment of low back pain: a placebo-controlled clinical trial to assess efficacy. Spine 2001;26:1411-16; discussion 17

29. Nath S, Nath CA, Pettersson K. Percutaneous lumbar zygapophysial (facet) joint neurotomy using radiofrequency current, in the management of chronic low back pain: a randomized double-blind trial. Spine 2008;33:1291-7.

30. van Kleef M, Barendse GA, Kessels A, et al. Randomized trial of radiofrequency lumbar facet denervation for chronic low back pain Spine (Phila Pa 1976) 1999;24:1937-42.

31. Patel N, Gross A, Brown L, et al. A randomized, placebo-controlled study to assess the efficacy of lateral branch neurotomy for chronic sacroiliac joint pain. Pain Med 2012;13:383-98.

32. Bradley JD, Heilman DK, Katz BP, et al. Tidal irrigation as treatment for knee osteoarthritis: a sham-controlled, randomized, double-blinded evaluation. Arthritis Rheum 2002;46:100-8.

33. Moseley JB Jr., Wray NP, Kuykendall D, et al. Arthroscopic treatment of osteoarthritis of the knee: a prospective, randomized, placebo-controlled trial. Results of a pilot study. Am J Sports Med 1996;24:28-34.

34. Sihvonen R, Paavola M, Malmivaara A, et al. Arthroscopic partia meniscectomy versus sham surgery for a degenerative meniscal tear. N Engl J Med 2013;369:2515-24.

35. Cobb LA, Thomas GI, Dillard DH, et al. An evaluation of internal-mammary-artery ligation by a double-blind technic. $N$ Engl $J$ Med 1959;260:1115-18.

36. Dimond EG, Kittle CF, Crockett JE. Comparison of internal mammary artery ligation and sham operation for angina pectoris. Am J Cardiol 1960;5:483-6.

37. Leon MB, Kornowski R, Downey WE, et al. A blinded, randomized, placebo-controlled trial of percutaneous laser myocardial revascularization to improve angina symptoms in patients with severe coronary disease. J Am Coll Cardiol 2005;46: 1812-19.

38. Salem M, Rotevatn S, Stavnes S, et al. Release of cardiac biochemical markers after percutaneous myocardial laser or sham procedures. Int J Cardiol 2005;104:144-51.

39. Salem M, Rotevatn S, Stavnes S, et al. Usefulness and safety of percutaneous myocardial laser revascularization for refractory angina pectoris. Am J Cardiol 2004;93:1086-91.

40. Cote $\mathrm{G}$, Imperiale T, Schmidt S, et al. Similar efficacies of biliary with or without pancreatic, sphincterotomy in treatment of idiopathic recurrent acute pancreatitis. Gastroenterology 2012;143:1502-09 e01.

41. Boelens O, Assen TV, Houterman S, et al. A double-blind, randomized, controlled trial on surgery for chronic abdominal pain due to anterior cutaneous nerve entrapment syndrome. Ann Surg 2013;257:845-9.

42. Swank D, Swank-Bordewijk S, Hop W, et al. Laparoscopic adhesiolysis in patients with chronic abdominal pain: a blinded randomised controlled multi-centre trial. Lancet 2003;361: 1247-51.

43. Abbott J, Hawe J, Hunter D, et al. Laparoscopic excision of endometriosis: a randomized, placebo-controlled trial. Fertil Steril 2004:82:878-84.

44. Jarrell J, Brant R, Leung W, et al. Women's pain experience predicts future surgery for pain associated with endometriosis. J Obstet Gynaecol Can 2007;29:988-91.

45. Jarrell J, Mohindra R, Ross S, et al. Laparoscopy and reported pain among patients with endometriosis. J Obstet Gynaecol Can 2005;27:477-85. 
46. Sutton CJ, Pooley AS, Ewen SP, et al. Follow-up report on a randomized controlled trial of laser laparoscopy in the treatment of pelvic pain associated with minimal to moderate endometriosis. Fertil Steril 1997:68:1070-4

47. Sutton CJ, Ewen SP, Whitelaw N, et al. Prospective, randomized, double-blind, controlled trial of laser laparoscopy in the treatment of pelvic pain associated with minimal, mild, and moderate endometriosis. Fertil Steril 1994;62:696-700.

48. Geenen JE, Hogan WJ, Dodds WJ, et al. The efficacy of endoscopic sphincterotomy after cholecystectomy in patients with sphincter-of-Oddi dysfunction. N Engl J Med 1989;320:82-7.

49. Toouli J, Roberts-Thomson IC, Kellow J, et al. Manometry based randomised trial of endoscopic sphincterotomy for sphincter of Oddi dysfunction. Gut 2000;46:98-102.

50. Dowson A, Mullen MJ, Peatfield R, et al. Migraine Intervention With STARFlex Technology (MIST) trial: a prospective, multicenter, double-blind, sham-controlled trial to evaluate the effectiveness of patent foramen ovale closure with STARFlex septal repair implant to resolve refractory migraine headache. Circulation 2008;117:1397-404

51. Guyuron B, Reed D, Kriegler JS, et al. A placebo-controlled surgical trial of the treatment of migraine headaches. Plast Reconstr Surg 2009:124:461-8.

52. Genco A, Cipriano M, Bacci V, et al. BioEnterics Intragastric Balloon (BIB): a short-term, double-blind, randomised, controlled, crossover study on weight reduction in morbidly obese patients. Int $J$ Obes (Lond) 2006;30:129-33.

53. Gersin KS, Rothstein RI, Rosenthal RJ, et al. Open-label, sham-controlled trial of an endoscopic duodenojejunal bypass liner for preoperative weight loss in bariatric surgery candidates. Gastrointest Endosc 2010;71:976-82.

54. Lindor KD, Hughes RW Jr., Ilstrup DM, et al. Intragastric balloons in comparison with standard therapy for obesity - a randomized, double-blind trial. Mayo Clin Proc 1987;62:992-6.

55. Martinez-Brocca MA, Belda O, Parejo J, et al. Intragastric balloon-induced satiety is not mediated by modification in fasting or postprandial plasma ghrelin levels in morbid obesity. Obes Surg 2007;17:649-57.

56. Mathus-Vliegen EM, Tytgat GN, Veldhuyzen-Offermans EA. Intragastric balloon in the treatment of super-morbid obesity. Double-blind, sham-controlled, crossover evaluation of 500-milliliter balloon. Gastroenterology 1990;99:362-9.

57. Mathus-Vliegen EMH, Tytgat GNJ. Gastro-oesophageal reflux in obese subjects: influence of overweight, weight loss and chronic gastric balloon distension. Scand J Gastroenterol 2002;37: 1246-52.

58. Mathus-Vliegen EMH, Tytgat GNJ. Intragastric balloon for treatment-resistant obesity: safety, tolerance, and efficacy of 1-year balloon treatment followed by a 1-year balloon-free follow-up. Gastrointest Endosc 2005;61:19-27.

59. Mathus-Vliegen EMH, Van Weeren M, Van Eerten PV. LOS function and obesity: the impact of untreated obesity, weight loss, and chronic gastric balloon distension. Digestion 2003;68:161-8.

60. Mathus-Vliegen LMH, Tytgat GNJ. Twenty-four-hour pH measurements in morbid obesity: effects of massive overweight, weight loss and gastric distension. Eur J Gastroenterol Hepatol 1996;8:635-40.

61. Meshkinpour H, Hsu D, Farivar S. Effect of gastric bubble as a weight reduction device: a controlled, crossover study. Gastroenterology 1988;95:589-92.

62. Rigaud D, Trostler N, Rozen R, et al. Gastric distension, hunger and energy intake after balloon implantation in severe obesity. Int $J$ Obes Relat Metab Disord 1995;19:489-95.

63. Corley DA, Katz P, Wo JM, et al. Improvement of gastroesophageal reflux symptoms after radiofrequency energy: a randomized, sham-controlled trial. Gastroenterology 2003;125:668-76.

64. Deviere J, Costamagna G, Neuhaus $\mathrm{H}$, et al. Nonresorbable copolymer implantation for gastroesophageal reflux disease: a randomized sham-controlled multicenter trial. Gastroenterology 2005; $128: 532-40$

65. Montgomery M, Hakanson B, Ljungqvist $\mathrm{O}$, et al. Twelve months' follow-up after treatment with the EndoCinch endoscopic technique for gastro-oesophageal reflux disease: a randomized, placebo-controlled study. Scand J Gastroenterol 2006;41: 1382-9.

66. Rothstein R, Filipi C, Caca K, et al. Endoscopic full-thickness plication for the treatment of gastroesophageal reflux disease: a randomized, sham-controlled trial. Gastroenterology 2006;131:704-12.

67. Schwartz MP, Wellink H, Gooszen HG, et al. Endoscopic gastroplication for the treatment of gastro-oesophageal reflux disease: a randomised, sham-controlled trial. Gut 2007;56:20-8.
68. Freed CR, Greene PE, Breeze RE, et al. Transplantation of embryonic dopamine neurons for severe Parkinson's disease. N Engl J Med 2001;344:710-19.

69. Gordon PH, Yu Q, Qualls C, et al. Reaction time and movement time after embryonic cell implantation in Parkinson disease. Arch Neurol 2004;61:858-61.

70. Greene PE, Fahn S. Status of fetal tissue transplantation for the treatment of advanced Parkinson disease. Neurosurg 2002;13:e3.

71. McRae C, Cherin E, Diem G, et al. Does personality change as a result of fetal tissue transplantation in the brain? J Neurol 2003;250:282-6.

72. McRae C, Cherin E, Yamazaki TG, et al. Effects of perceived treatment on quality of life and medical outcomes in a double-blind placebo surgery trial. Arch Gen Psychiatry 2004;61:412-20.

73. Nakamura T, Dhawan V, Chaly T, et al. Blinded positron emission tomography study of dopamine cell implantation for Parkinson's disease. Ann Neurol 2001;50:181-7.

74. Olanow CW, Goetz CG, Kordower JH, et al. A double-blind controlled trial of bilateral fetal nigral transplantation in Parkinson's disease. Ann Neurol 2003;54:403-14.

75. Friedman M, Schalch $\mathrm{P}$, Lin HC, et al. Palatal implants for the treatment of snoring and obstructive sleep apnea/hypopnea syndrome. Otolaryngol Head Neck Surg 2008;138:209-16.

76. Koutsourelakis I, Georgoulopoulos G, Perraki E, et al. Randomised trial of nasal surgery for fixed nasal obstruction in obstructive sleep apnoea. Eur Respir J 2008;31:110-17.

77. Geldis JR, Nichols JJ. The impact of punctal occlusion on soft contact lens wearing comfort and the tear film. Eye Contact Lens 2008:34:261-5.

78. Slusser TG, Lowther GE. Effects of lacrimal drainage occlusion with nondissolvable intracanalicular plugs on hydrogel contact lens wear. Optom Vis Sci 1998;75:330-8.

79. Castro M, Rubin AS, Laviolette M, et al. Effectiveness and safety of bronchial thermoplasty in the treatment of severe asthma: a multicenter, randomized, double-blind, sham-controlled clinical trial. Am J Respir Crit Care Med 2010;181:116-24.

80. Curran WS, Graham WG. Long term effects of glomectomy. Followup of a double-blind study. Am Rev Respir Dis 1971;103:566-8.

81. Curran WS, Oser JF, Longfield AN, et al. Glomectomy for severe bronchial asthma. A double-blind study. Am Rev Respir Dis 1966;93:84-9.

82. Bajbouj M, Becker V, Eckel F, et al. Argon plasma coagulation of cervical heterotopic gastric mucosa as an alternative treatment for globus sensations. Gastroenterology 2009;137:440-4.

83. Bretlau $\mathrm{P}$, Thomsen J, Tos $\mathrm{M}$, et al. Placebo effect in surgery for Meniere's disease: a three-year follow-up study of patients in a double blind placebo controlled study on endolymphatic sac shunt surgery. Am J Otol 1984;5:558-61.

84. Davys HJ, Turner DE, Helliwell PS, et al. Debridement of plantar callosities in rheumatoid arthritis: a randomized controlled trial. Rheumatology (Oxford) 2005;44:207-10.

85. Larson TR, Blute ML, Bruskewitz RC, et al. A high-efficiency microwave thermoablation system for the treatment of benign prostatic hyperplasia: results of a randomized, sham-controlled, prospective, double-blind, multicenter clinical trial. Urology 1998:51:731-42.

86. Thomsen J. Placebo effect in surgery for Meniere's disease. Arch Otolaryngol 1981;107:271-7.

87. Thomsen J, Bretlau P, Tos M, et al. Placebo effect in surgery for Meniere's disease: three-year follow-up. Otolaryngology-Head \& Neck Surgery 1983;91:183-6.

88. Thomsen J, Bretlau P, Tos M, et al. Endolymphatic sac-mastoid shunt surgery. A nonspecific treatment modality? Ann Otol Rhinol Laryngol 1986;95:32-5.

89. Winters C, Artnak EJ, Benjamin SB, et al. Esophageal bougienage in symptomatic patients with the nutcracker esophagus. A primary esophageal motility disorder. JAMA 1984;252:363-6.

90. Rodriguez L, Reyes E, Fagalde P, et al. Pilot clinical study of an endoscopic, removable duodenal-jejunal bypass liner for the treatment of type 2 diabetes. Diabetes Technol Ther 2009;11: 725-32.

91. Krogsboll LT, Hrobjartsson A, Gotzsche PC. Spontaneous improvement in randomised clinical trials: meta-analysis of three-armed trials comparing no treatment, placebo and active intervention. BMC Med Res Methodol 2009;9:1.

92. Wartolowska K, Judge A, Hopewell S, et al. Use of placebo controls in the evaluation of surgery: systematic review. BMJ 2014;348: g3253.

93. Robinson ME, Gagnon CM, Riley JL III, et al. Altering gender role expectations: effects on pain tolerance, pain threshold, and pain ratings. J Pain 2003;4:284-8. 
94. Vase L, Robinson ME, Verne GN, et al. The contributions of suggestion, desire, and expectation to placebo effects in irritable bowel syndrome patients. An empirical investigation. Pain 2003;105:17-25.

95. Meissner K, Distel H, Mitzdorf U. Evidence for placebo effects on physical but not on biochemical outcome parameters: a review of clinical trials. BMC Med 2007;5:3.

96. Mora M, Nestoriuc $\mathrm{Y}$, Rief $\mathrm{W}$. Lessons learned from placebo groups in antidepressant trials. Philos Trans R Soc Lond B Biol Sci 2011;366:1879-88.
97. Enck $\mathrm{P}, \mathrm{Klosterhalfen} \mathrm{S}$. The placebo response in functional bowel disorders: perspectives and putative mechanisms. Neurogastroenterol Motil 2005;17:325-31.

98. Leucht S, Hierl S, Kissling W, et al. Putting the efficacy of psychiatric and general medicine medication into perspective: review of meta-analyses. Br J Psychiatry 2012;200:97-106.

99. Wartolowska K, Beard D, Carr A. Attitudes and beliefs about placebo surgery among orthopedic shoulder surgeons in the United Kingdom. PLOS ONE 2014;9:e91699. 